\title{
Using SAR Data to Detect Wheat Irrigation Supply in an Irrigated Semi-arid Area
}

\author{
Tarik Benabdelouahab ${ }^{1}$, Dominique Derauw ${ }^{2}$, Hayat Lionboui ${ }^{1}$, Rachid Hadria ${ }^{1}$, Bernard Tychon ${ }^{3}$, \\ Abdelghani Boudhar ${ }^{4}$, Riad Balaghi $^{1}$, Youssef Lebrini ${ }^{4}$, Hamid Maaroufi $^{4} \&$ Christian Barbier $^{2}$ \\ ${ }^{1}$ National Institute of Agronomic Research, Rabat, Morocco \\ ${ }^{2}$ Centre spatial de Liège (CSL), Angleur, Belgium \\ ${ }^{3}$ Liège University (ULg), Arlon campus, Belgium \\ ${ }^{4}$ Faculté des Sciences et Technique (FST), Beni-Mellal, Morocco \\ Correspondence: Tarik Benabdelouahab, National Institute of Agronomic Research, Rabat, Morocco. E-mail: \\ Tarik.benabdelouahab@gmail.com
}

Received: July 23, 2018 Accepted: October 13, $2018 \quad$ Online Published: December 15, 2018

doi:10.5539/jas.v11n1p21 URL: https://doi.org/10.5539/jas.v11n1p21

\begin{abstract}
The objective of this study was to use SAR (sensitivity of Synthetic Aperture Radar) data to detect the supply of irrigation water during the anthesis and grain-filling phenological stages of wheat in the irrigated Tadla perimeter of Morocco. Backscattering coefficients were derived from four ERS-1 (European Remote-Sensing Satellite-1) images acquired between 31 March and 12 April 2011 and were compared with the irrigation water invoices database. The analysis showed that there were significant changes in backscattering values caused by irrigation, with average values ranging between 0.11 and $3.11 \mathrm{~dB}$. A reference level of $0.52 \mathrm{~dB}$ was established for differentiating between (recently; up to 4 days) irrigated and non-irrigated plots. We also set an interval of 5 days for the acquisition of SAR images in order to ensure continuous monitoring of the irrigated wheat plots over time. The study showed that radar data contain important information for the assessment of irrigation supplies during the cropping season, which could help regional decision-support systems to monitor and control irrigation supplies over large areas.
\end{abstract}

Keywords: backscattering, irrigation, radar, SAR, irrigated area, semi-arid region

\section{Introduction}

Irrigated areas throughout the world are facing increasing pressure due mainly to erratic precipitation regimes (Dore, 2005), long dry periods and rapidly growing population demands. In this context, the effective management and monitoring of irrigated areas require a good understanding of the spatial and temporal processes governing agricultural systems.

Managing and monitoring an irrigated area effectively can be done by analyzing these processes over an entire crop cycle and a large agricultural area where the surface is heterogeneous (various types of crops, classes of soil and management approaches) in order to assess the overall impact of crop management practices (Lionboui, Benabdelouahab, Hasib, Elame, \& Boulli, 2018).

In Morocco, cereals are one of the major grain crops grown and they hold an important place in the agricultural production systems, occupying $75 \%$ of the cultivated area and accounting for $10-20 \%$ of the agricultural Gross Domestic Product (GDP). Nevertheless, yields remain low and fluctuate from one area to another and one season to another because of varying water management, field management and weather conditions (Benabdelouahab et al., 2016).

Given the importance of wheat production in semi-arid areas where water is the main limiting factor, large-scale irrigation of wheat is common practice. There is therefore a need for good management of irrigation supplies in order to improve irrigation scheduling and prevent water stress from adversely affecting yield (Lionboui, Benabdelouahab, Elame, Hasib, \& Boulli, 2016). Remote sensing satellites can be used for monitoring land surface changes because of their extensive coverage capacity and frequent revisits (Benabdelouahab et al., 2015; Fieuzal et al., 2011; Kalluri, Gilruth, \& Bergman, 2003; Ozdogan, Yang, Allez, \& Cervantes, 2010). 
Several studies have investigated the sensitivity of Synthetic Aperture Radar (SAR) imagery to surface parameters (soil cover, surface water content and roughness) (Nicolas Baghdadi, Boyer, Todoroff, El Hajj, \& Bégué, 2009; Feng, Chen, Dong, Wang, \& Meng, 2013). SAR sensitivity is linked to the sensor characteristics (frequency, incidence and polarization). Many authors (Hadria et al., 2009; Mattia et al., 2003; McNairn, Merzouki, Pacheco, \& Fitzmaurice, 2012) have demonstrated the potential of SAR for monitoring agricultural factors that have a significant influence on backscatter coefficients.

The recent launch of Sentinel-1, which offers both high spatial resolution and frequent revisits, could be interesting (Aulard-Macler, 2011; Snoeij et al., 2008). It is still difficult, however, to acquire synchronous multi-sensor time series in order to analyze satellite data sensitivity over comparable surface conditions. C-band data are available from the ERS-1/2, EnviSat, Radarsat-1/2 and Sentinel-1 systems.

For wheat canopies and topsoil moisture, the sensitivity of radar backscattering coefficients was demonstrated by Mattia et al. (2003) and Picard, Le Toan, and Mattia (2003). Some attempts have been made to use simplified relationships between SAR backscattering coefficients and wheat canopy characteristics (Dente, Satalino, Mattia, \& Rinaldi, 2008; Mattia et al., 2003). Few authors, however, have tried to apply the radar on a large scale and in a representative context (Fieuzal, Baup, \& Marais-Sicre, 2013).

At C-band frequency, the temporal behavior of wheat in different studies (Mattia et al., 2003; Saich \& Borgeaud, 2000) shows similar global trends for the same study site. Recent studies have proposed multi-sensor approaches for irrigation management purposes by combining optical and radar images (Fieuzal et al., 2011; Hadria et al., 2009; Hadria et al., 2010).

In irrigation monitoring, it is thought that the backscattering signal generated from SAR images reacts to changes in surface moisture (Hadria et al., 2009), which could be important indicator to detect irrigation inputs and monitoring surface moisture on a large scale and in a realistic context during the anthesis and grain-filling phenological stages of wheat. This information could be very useful in improving national grain yield forecast models that currently do not take into account production from irrigated areas, despite the fact that they occupy over 1million ha. Irrigation water supply data (time, duration and irrigated area) could be integrated into yield forecast models in order to improve their accuracy.

In this context, we conducted an analysis of a large number of agricultural plots using time series of SAR images in order to assess their sensitivity to surface moisture. This was done by evaluating the values of the backscatter signal compared with the variability of the surface moisture that is closely related to the irrigation supply program at wheat plot level (databases dates irrigation).

\section{Methodology}

Previous studies using SAR images have shown the potential of using backscattering signals to monitor vegetation water content and surface soil moisture via a simple linear relationship and one incidence-angle data (Fieuzal et al., 2011; Mattia et al., 2003; Zribi et al., 2005). Drawing on these studies, the methodology adopted in our study sought to detect irrigation water supplies to the wheat crop using SAR data.

\subsection{Study Site}

The irrigated Tadla perimeter (Figure 1) is in central Morocco, between the Atlantic coast in the north-west and the Atlas Mountains in the south-east ( $32^{\circ} 23^{\prime} \mathrm{N}$ latitude; $6^{\circ} 31^{\prime} \mathrm{W}$ longitude; $445 \mathrm{~m}$ above sea level). The studied area is characterized by a semi-arid climate; the annual average temperature is about $19{ }^{\circ} \mathrm{C}$, with a large inter-seasonal variation ( $\max =38{ }^{\circ} \mathrm{C}$ in August and $\min =3.5^{\circ} \mathrm{C}$ in January). The average annual precipitation is about $300 \mathrm{~mm}$ (average over the 1970-2010 period), with significant inter-annual variation (from $130 \mathrm{~mm}$ to $600 \mathrm{~mm})$. 


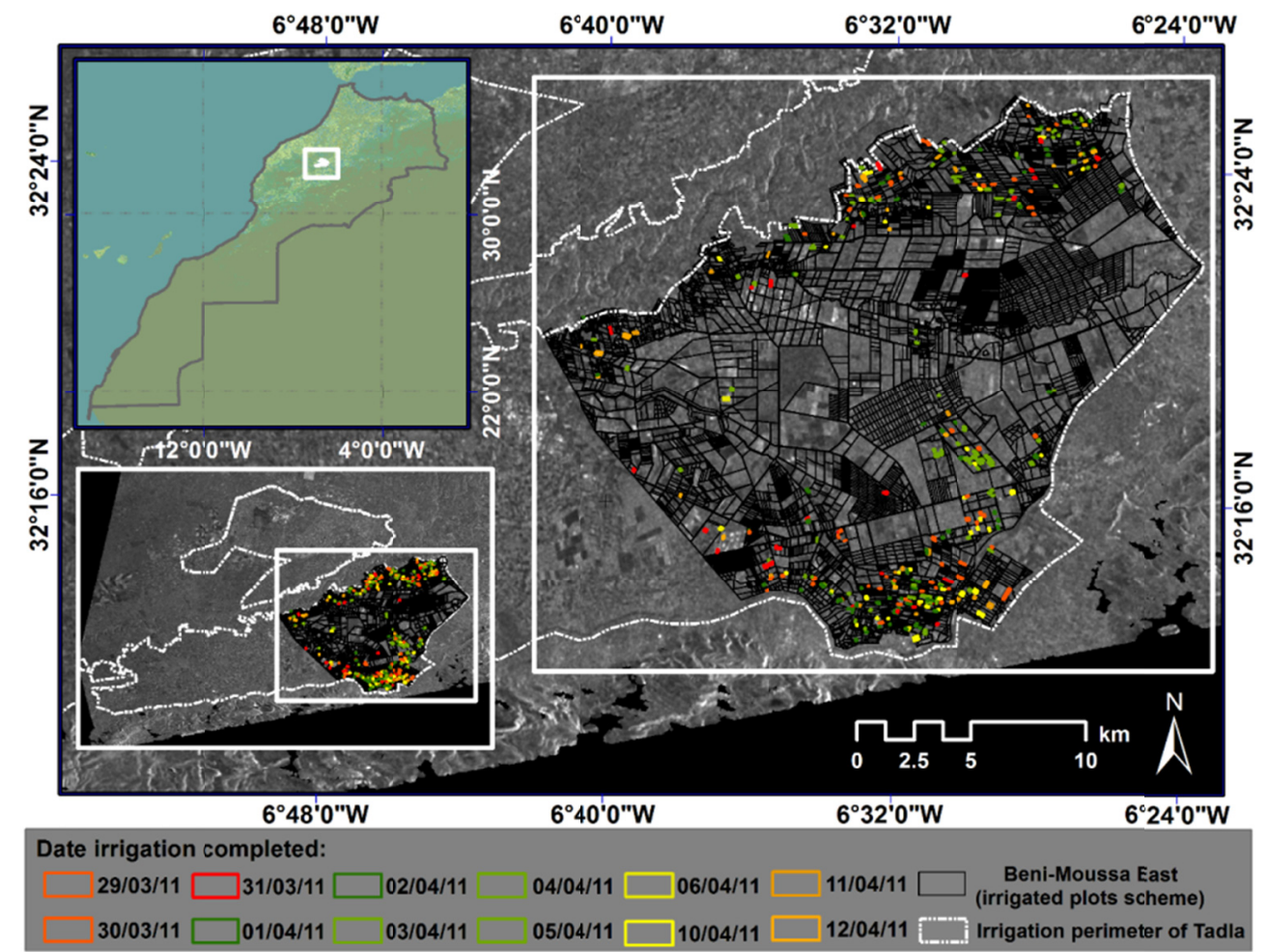

Figure 1. Location of the irrigated area (upper left inset shows a map of Morocco; the plot plan is indicated by black lines and the studied irrigated plots are multicolored according to the date the irrigation was completed)

The irrigated Tadla perimeter is managed by the Regional Office for the Agricultural Development of Tadla (ORMVAT). The studied area is in Beni-Moussa East, covers 40,000 ha and is characterized by flat topography.

Cereal crops are one of the main crops in the study area. In the 2010-2011 cropping season, wheat occupied about $17 \%(6,730 \mathrm{ha})$ of the total cultivated area of Beni-Moussa East. It is usually sown between mid-November and mid-January, depending on when the first significant precipitation occurs, and is harvested between May and June.

We studied those wheat plots that were irrigated between 29/03/2011 and 12/04/2011. The studied plots represented 3.5\% (235.5 ha) of the total area under wheat in Beni-Moussa East. Irrigation is applied here using the traditional surface flood method. During the growing season, wheat is irrigated between two and five times, depending on rainfall conditions.

\subsection{Ground and Satellite Data}

\subsubsection{Ground Data}

We used the invoices of irrigation water database intended for farmers for the period between 28/03/2011 and $15 / 04 / 2011$ corresponding to the period when images were acquired in the 2010/2011 cropping season. This database is organized and managed by ORMVAT, which is in charge of irrigation water management in the area. The database holds data on periods of irrigation (start and end), plots and the amount of water used by farmers across the studied area. During the crop development stages of anthesis and grain filling, plot conditions (phenological stages, irrigation techniques) were fairly homogeneous.

\subsubsection{Climate Data}

Daily meteorological data was obtained from the Affourer station, which is part of the Moroccan National Weather network and is located in the study area (Figure 2). Rainfall was measured with tipping bucket rain gauges. The collected data showed that there was no precipitation between 16/03/2011 and 21/04/2011. The change in backscattering values of SAR images was therefore due only to irrigation water supplies to the wheat crop in the study area. 


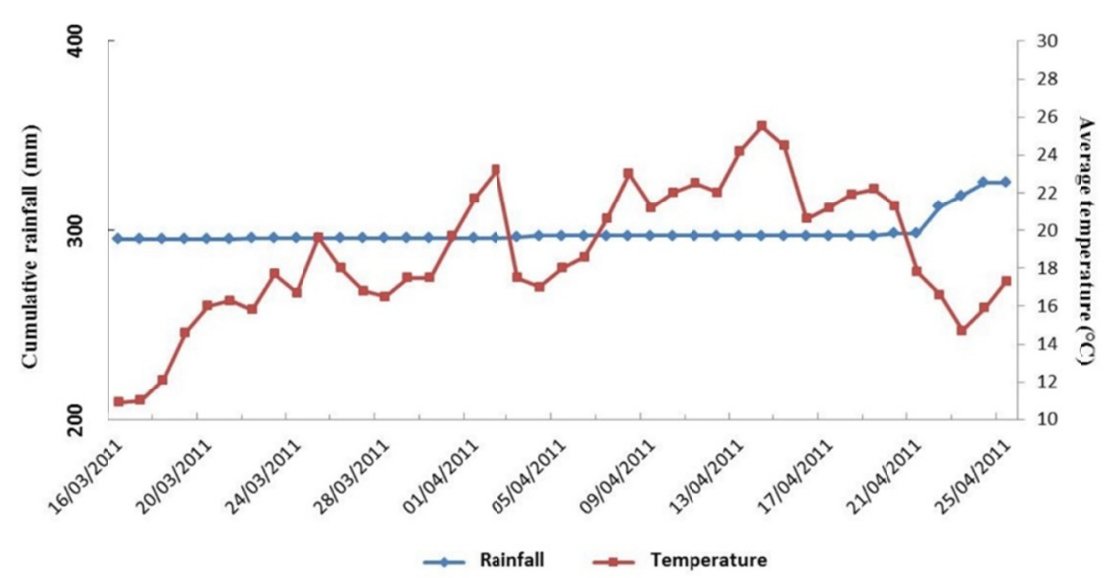

Figure 2. Daily meteorological data for the study area

\subsection{Radar Data: Time Series of SAR Images}

Between 31 March 2011 and 12 April 2011, four SAR images were acquired, all in the descending pass. The images were acquired in dual polarizations (VV) at medium incidence angles $\left(23.3^{\circ}\right)$. The ERS-2 satellite is a SAR instrument operating at $\mathrm{C}$-band $(\mathrm{f}=5.3 \mathrm{GHz}, \lambda \approx 5.6 \mathrm{~cm})$. Figure 1 gives an example of a SAR image of the study area.

\subsubsection{Amplitude Images}

Time series of backscattering amplitude images were generated over the study area based on Single-Look Complex images from the ERS-2 archives. Using the CSL InSAR Suite (CIS) developed by the Centre Spatial de Liège (Derauw, 1999), an amplitude image was computed and geoprojected with a final ground sampling of $30 \times$ $30 \mathrm{~m}$ (Grandchamp \& Cavassilas, 1997). The step-by-step process was as follows:

$>$ Amplitude image reduction: Amplitude was computed before geoprojection using box averaging to reduce the speckle noise by the incoherent summation of backscattering values.

Coregistration: In order to generate usable time series, we performed coarse and then fine coregistration in relation to a global master acquisition. The chosen global master acquisition was the one from 31 March 2011. Coarse coregistration is performed by correlating the amplitude windows centered on target anchor points regularly distributed on the master image. Fine coregistration, when applicable, is performed through local coherence maximization.

Interpolation: Slave images were interpolated with regard to the computed transform in order to superimpose them on the master one and allow the SAR products to be computed. After these steps, the CIS tool computed the amplitude images, the interferogram and the coherence image, in addition to the geoprojection of these products.

\subsubsection{Backscatter Coefficient Calculation and Georeferencing}

Amplitude images are not calibrated and do not provide information on the backscattering coefficient. Image calibration was performed using Equations 1 and 2, below (Laur et al., 2002). This step allows the amplitude digital number (DN) to be converted into the backscattering coefficient in decibels $(\mathrm{dB})$ for each pixel.

Following radiometric calibration, all images are then georeferenced using ENVI 5 software.

$$
\begin{gathered}
\sigma_{i, j}^{0}=\frac{D N_{i, j}^{2}}{K} \times \frac{1}{G\left(\theta_{i, j}\right)^{2}} \times\left(\frac{R_{i, j}}{R_{r e f}}\right)^{3} \cdot \sin \left(\alpha_{i, j}\right) \\
\sigma^{0}(d B)=10 \log \sigma_{i, j}^{0}
\end{gathered}
$$

In Equation 1, backscattering coefficients $(\sigma 0)$ are derived from the digital number $(\mathrm{DN})$ of the pixels $(\mathrm{i}, \mathrm{j})$ and from the parameters of the images, such as the local incidence angle $(\alpha \mathrm{i}, \mathrm{j})$, the slant range position $(\mathrm{Ri}, \mathrm{j})$ and the look angle corresponding to pixel ' $\mathrm{i}, \mathrm{j}$ ' $(\theta \mathrm{i}, \mathrm{j})$, and the constant parameters come from the ERS SAR calibration document (the calibration factor) $[\mathrm{K}]$, the gain $\left.\left[\mathrm{G}(\theta \mathrm{i}, \mathrm{j})^{2}\right)\right]($ Laur et al., 2002).

\subsection{Delimitation of the Cereal Area}




\subsubsection{Satellite Images and Their Processing}

One SPOT-5 HRV satellite image was acquired on 15 April 2011 (Table 1), when the soil was completely covered by vegetation. It spanned the period between anthesis (March) and grain filling (April) in the 2010-2011 cropping season.

Table 1. List of acquired SPOT-5 HRV images and their characteristics

\begin{tabular}{lllll}
\hline Acquisition date & Cropping season & Sensor & Wavelength $(\mathrm{nm})$ & Resolution $(\mathrm{m})$ \\
\hline \multirow{3}{*}{$15 / 04 / 2011$} & \multirow{2}{*}{$2010 / 2011$} & SPOT-5 & Green: $500-590$ & Red: 5 \\
& HRV & Red: $610-680$ & Green: 5 \\
& & NIR: $780-890$ & NIR: 5 \\
\hline
\end{tabular}

The processing level of the acquired images was (1B), which included radiometric and geometric corrections.

\subsubsection{Supervised Classification}

In order to define the cereal area, we used a maximum likelihood classification method that is a widely used supervised pixel-based method (Ouyang et al., 2011).

Training areas representative of the land cover classes were selected in order to develop class signature files. For each image, training areas were defined based on a field survey, expert field knowledge and ancillary data (tree crops mask and irrigation canals). Two thirds of the training areas were used in the classification process, the remaining one third in the accuracy assessment. The main classes were: cereals; bare soil; industrial crops; perennial crops; and arboriculture.

For the wheat class, we selected a sufficient number of pixels representing $1.08 \%$ of the total pixels $(500,123$ pixels) (Yang, Everitt, \& Murden, 2011). We performed the separability analysis, using the Jeffries-Matusita distance, for training samples in the final classification scheme with values of separability between 1.99 and 2, indicating good class separation.

The contingency matrix was used to evaluate the percentage of sampled pixels classified as expected. User accuracy and producer accuracy regarding the wheat class were $87.8 \%$ and $86.73 \%$, respectively. The overall accuracy assessment and Kappa values were $85.7 \%$ and $0.84 \%$, respectively, indicating good classification.

\subsection{Integration and Intersection of Ground and Satellite Data}

From the SAR data we obtained an amplitude time series. We also analyzed archival data of the irrigation supply schedule used by farmers in the irrigated Tadla perimeter at the plot level. The archival data was provided by ORMVAT.

The backscatter parameter from the ERS-2 images was averaged for each of the 341 training plots. This was followed by crossing all the information layers to monitor and analyze the spatiotemporal evolution of backscattering intensity, depending on irrigation water supplies used by farmers for their wheat plots. Figure 3 summarizes these steps. 


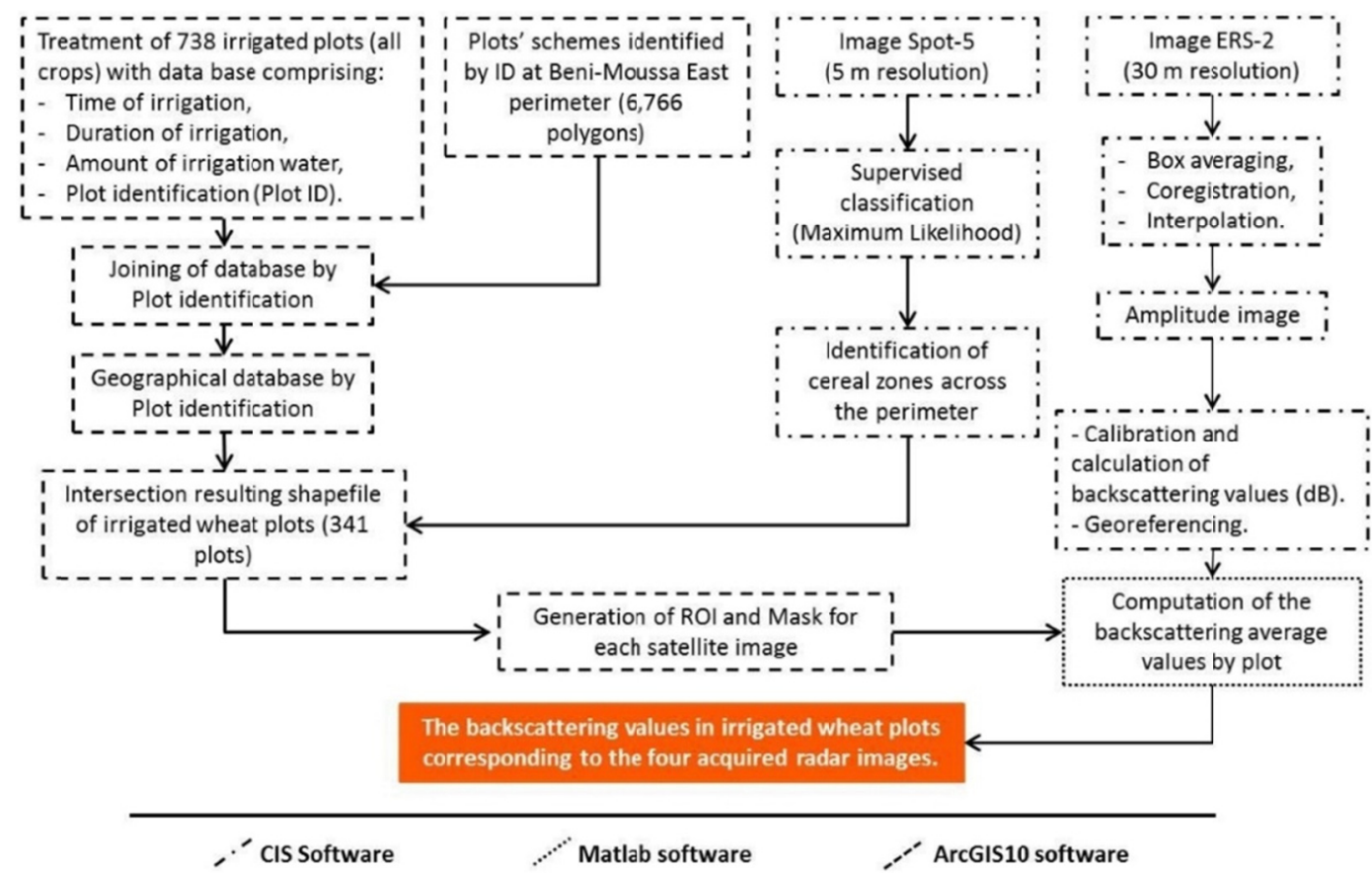

Figure 3. Schematic diagram illustrating field data and SAR data processing

\subsection{Data Analysis}

A reference level was established for differentiating between irrigated and non-irrigated plots. This step aims to set an interval time for the acquisition of SAR images in order to ensure continuous monitoring of the irrigated wheat plots over time. For this a statistical analysis has been implemented to highlight these parameters. Linear regression has been proposed for the data set for non-irrigated plot data (this category includes irrigated plots for more than 5 days).

\section{Results and Discussion}

Amplitude images were derived from the ERS-2 images acquired on 31/03/11, 03/04/11, 06/04/11 and 12/04/11. These data were used to assess the potential of SAR data for detecting irrigation and to analyze the radar backscattering as a function of changes in wheat water content and soil moisture. Table 2 shows the measured backscattering values for all plots for which irrigation dates were made available. For each SAR acquisition date, backscattering values are ordered and classified according to the known date of irrigation completion. Clear changes and trends in backscattering values can be seen. These changes are subsequent to irrigation water applied to the plots and to the heterogeneity of their moisture condition. As shown in Table 2, the backscattering values for all plots varied between 0.11 to $3.11 \mathrm{~dB}$.

As shown in Figure 4, the highest backscatter values occurred when the SAR acquisition date corresponded with the irrigation completion date.

In this case, the average backscattering values for all plots, whatever their size, varied between 2.79 and $3.11 \mathrm{~dB}$ (Figure 4). It is important to note that the total number of plots was 341, of which 282 were smaller than 1 ha and 59 were larger than 1 ha.

The variation was more important for plots with an area between 1.01 and 4.42 ha, exhibiting a standard deviation of $1.11 \mathrm{~dB}$, unlike plots smaller than 1 ha which had a small deviation of $0.19 \mathrm{~dB}$. This large variation was due to the duration of irrigation and the timing of the start of irrigation, which affected the response of backscatter plots and the fall in backscattering values in already irrigated plots, given that the flood irrigation takes 1-2 days ha ${ }^{-1}$. 


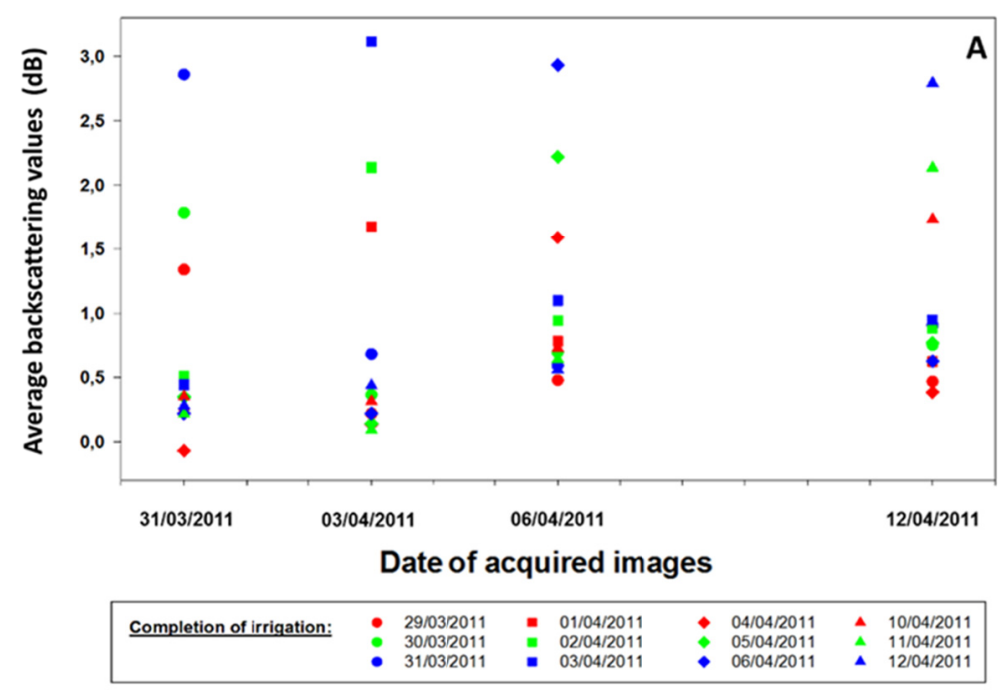

Figure 4. Potential of SAR data to detect irrigated plots (A: All plots)

For plots with a gap of 1-2 days between the date of the end of irrigation and the date of image acquisition, the backscattering levels ranged from 1.79 and $2.22 \mathrm{~dB}$ and from 1.34 to $1.74 \mathrm{~dB}$ for gaps of 1 and 2 days, respectively. Non-irrigated plots or plots irrigated more than 2 days before SAR acquisition showed backscattering values that were generally lower than $0.52 \mathrm{~dB}$.

This analysis confirms the clear relationship between $\sigma 0 \mathrm{VV}$ and irrigation water supplies. The variation in radar backscattering coefficients can therefore be related mainly to changes in wheat water content and soil moisture induced, in our case, by irrigation. These results were confirmed by Mattia et al. (2003), who found a linear correlation between backscattering coefficients and fresh biomass not exceeding 2,500 g/m2. A study conducted by N. Baghdadi, Aubert, and Zribi (2012) showed that the error (RMSE) in retrieved soil moisture observed at C-band was about $6 \%$ for a single incidence angle of $20^{\circ}$.

As shown in Figure 5, backscattering values can also be ordered with regard to the time gap between the SAR acquisition date and the irrigation completion date. This figure shows the responses of backscatter wheat plots to moisture changes in the vegetation cover and soil after an irrigation event. If the gap is zero (i.e., when irrigation ends on the SAR acquisition date), the backscattering values are high. This is true whatever the plot size. Plots smaller or equal than 1 ha or larger than 1 ha had average backscattering values of 3.08 and 2.44, respectively. The average backscattering value for all plots, whatever their size, was $2.92 \mathrm{~dB}$.

There was a discrepancy in average backscattering values between irrigated plots smaller than 1 ha and those larger than 1 ha of $0.6 \mathrm{~dB}$. The difference between the average backscattering value when there was no gap time and when there was a lag of 1 day was $0.6 \mathrm{~dB}$ for plots larger than 1 ha and about $1 \mathrm{~dB}$ for plots smaller than 1 ha. This result tends to confirm the effect of plot non-uniformity on backscatter values. 


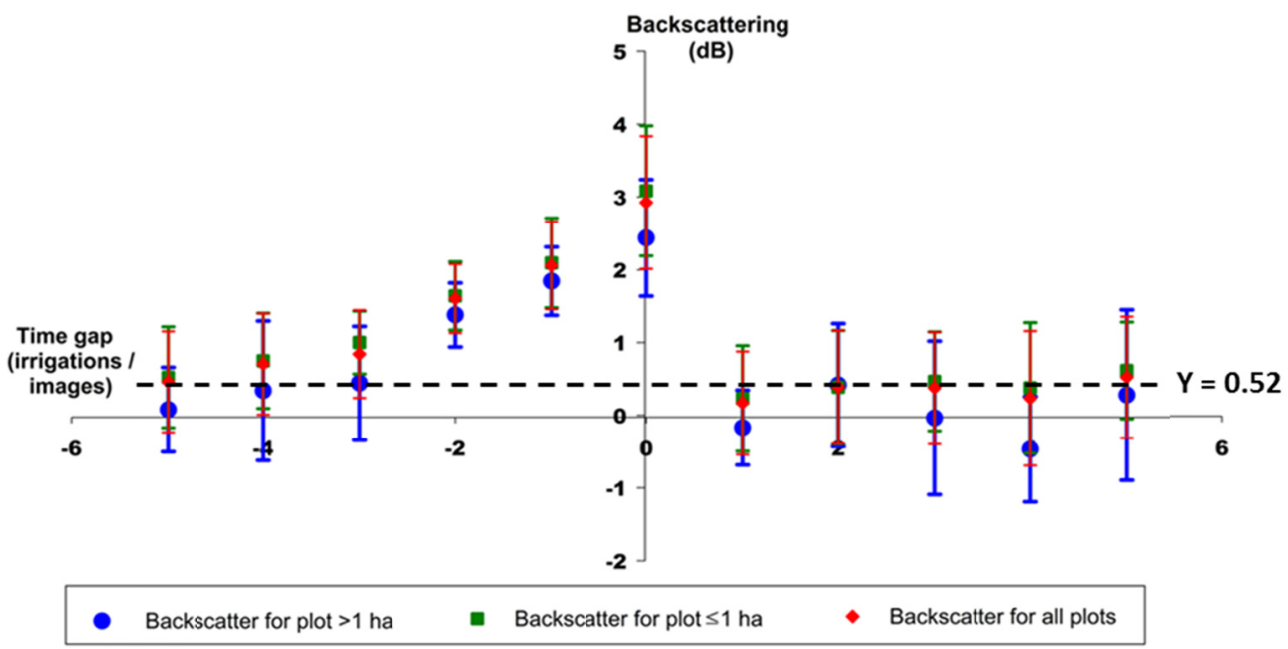

Figure 5. Evolution of backscattering values with regard to the time gap between irrigation time and satellite image acquisition. No gap means that irrigation time is the date of the satellite pass and a gap indicates the difference in days between irrigation and satellite pass (negative gap: irrigated plots; positive gap: non-irrigated plots)

Where the time gap was 1 day or more, there was a decrease in average backscatter values from irrigated wheat plots, varying between 1.34 and $2.22 \mathrm{~dB}$ for all plots.

From the third day of the irrigation, backscatter values fell below $0.52 \mathrm{~dB}$, which was close or equivalent to non-irrigated plots. Figure 8 illustrates this adjustment which defines the reference value (the threshold) considering the confidence interval of the $95 \%$ regression line. The backscatter value stabilizes with a similar behavior between irrigated plots for more than 5 days and the effect is no longer apparent and those non-irrigated.

The value of $0.52 \mathrm{~dB}$ can therefore be considered as a reference threshold that distinguishes between, on the one hand, irrigated plots and, on the other, non-irrigated plots and plots irrigated for more than 2 days. These results can be generalized at the regional level for the studied period, especially where wheat plot conditions are fairly homogeneous.

The time resolution proved to be a limiting factor for the continuous monitoring of the irrigated wheat plots, in that it was no longer possible to detect irrigation from the fourth day onwards (gap $=-4$ ), as shown in Figure 2. SAR images therefore need to be acquired at a maximum interval of 5 days (time resolution $=5$ ).

The results showed that SAR technology has great potential for irrigation management and could have an important agricultural-economic impact, if acquisition frequency can be increased and the prices of SAR images can be reduced. In the future, the use of SAR satellites looks promising for since the launch of other satellites is expected in the coming years.

In general, remote sensing tools are one of the best ways to monitor large agricultural areas, and research should be done on improving the mastery and application of SAR remote sensing in agriculture. In the case of irrigated areas, SAR images offer great potential for detecting changes and monitoring the water content of the surface and biomass in irrigated areas, whatever the plot size.

\section{Conclusion}

This study sought to assess the potential of SAR data for detecting irrigation supplies and to analyze the radar backscattering coefficients as a function of changes in wheat water content and soil moisture throughout the cropping season in irrigated semi-arid areas. The measured backscattering values showed a clear decreasing trend with regard to the time gap between irrigation completion date and image acquisition date. After 3 or more days between irrigation completion and SAR acquisition, a backscattering value of $0.52 \mathrm{~dB}$ or lower was observed, the same as the value observed for non-irrigated plots. A reference level of $0.52 \mathrm{~dB}$ could therefore be set for differentiating between irrigated and non-irrigated plots.

The study showed that in order to ensure continuous monitoring over time of irrigated wheat plots, an interval 3 days between the acquisitions of SAR images is required. This parameter could be used to compare and map 
vegetation water content and surface moisture at local and regional level in the irrigated Tadla perimeter. These results show that radar signal behavior can be generalized, especially where wheat plot conditions are fairly homogeneous.

SAR backscattering signal analysis shows potential for improving irrigation monitoring, detecting irrigation supplies and understanding surface water content changes at the field and regional levels in the study area.

Our findings need to be applied to other crops and other areas in order to test the validity of the proposed methodology.

\section{Acknowledgements}

This work was supported by the Belgian Technical Cooperation Agency, ISIS program of the National Centre for Space Studies (CNES), the Centre Spatial de Liège and the ORMVAT (Office Régionale de Mise en Valeur Agricole de Tadla). The acquisition of ERS-2 images was supported by the ESA program. The authors are indebted to the staff of the Regional Centre for Agronomic Research of Tadla for their collaboration and to Jaafar Belkouchi, Riani Abdelhamid and Abdul Aziz Diouf for their valuable help.

\section{References}

Aulard-Macler, M. (2011). Sentinel-1 Product Definition (p. 129). ESA.

Baghdadi, N., Aubert, M., \& Zribi, M. (2012). Use of TerraSAR-X data to retrieve soil moisture over bare soils agricultural fields. IEEE Transactions on Geoscience and Remote Sensing Letters, 9(3), 512-516. https://doi.org/10.1109/LGRS.2011.2173155

Baghdadi, N., Boyer, N., Todoroff, P., El Hajj, M., \& Bégué, A. (2009). Potential of SAR sensors TerraSAR-X, ASAR/ENVISAT and PALSAR/ALOS for monitoring sugarcane crops on Reunion Island. Remote Sensing of Environment, 113(8), 1724-1738. https://doi.org/10.1016/j.rse.2009.04.005

Benabdelouahab, T., Balaghi, R., Hadria, R., Lionboui, H., Djaby, B., \& Tychon, B. (2016). Testing Aquacrop to Simulate Durum Wheat Yield and Schedule Irrigation in a Semi-Arid Irrigated Perimeter in Morocco. Irrigation and Drainage, 65(5), 631-643. https://doi.org/10.1002/ird.1977

Benabdelouahab, T., Balaghi, R., Hadria, R., Lionboui, H., Minet, J., \& Tychon, B. (2015). Monitoring surface water content using visible and short-wave infrared SPOT-5 data of wheat plots in irrigated semi-arid regions. International Journal of Remote Sensing, 36(15), 4018-4036. https://doi.org/10.1080/01431161. 2015. 1072650

Dente, L., Satalino, G., Mattia, F., \& Rinaldi, M. (2008). Assimilation of leaf area index derived from ASAR and MERIS data into CERES-Wheat model to map wheat yield. Remote Sensing of Environment, 112(4), 1395-1407. http://doi.org/10.1016/j.rse.2007.05.023

Derauw, D. (1999). Phasimétrie par Radar à Synthèse d'Ouverture: Théorie et applications. Université de LIEGE, Liège.

Dore, M. H. I. (2005). Climate change and changes in global precipitation patterns: What do we know? Environment International, 31(8), 1167-1181. https://doi.org/10.1016/j.envint.2005.03.004

Feng, H., Chen, C., Dong, H., Wang, J., \& Meng, Q. (2013). Modified Shortwave Infrared Perpendicular Water Stress Index: A Farmland Water Stress Monitoring Method. Journal of Applied Meteorology and Climatology, 52(9), 2024-2032. https://doi.org/10.1175/jamc-d-12-0164.1

Fieuzal, R., Baup, F., \& Marais-Sicre, C. (2013). Monitoring Wheat and Rapeseed by Using Synchronous Optical and Radar Satellite Data-From Temporal Signatures to Crop Parameters Estimation. Advances in Remote Sensing, 2, 162-180. https://doi.org/10.4236/ars.2013.22020

Fieuzal, R., Duchemin, B., Jarlan, L., Zribi, M., Baup, F., Merlin, O., ... Garatuza-Payan, J. (2011). Combined use of optical and radar satellite data for the monitoring of irrigation and soil moisture of wheat crops. Hydrology and Earth System Sciences, 15(4), 1117-1129. https://doi.org/ 10.5194/hess-15-1117-2011

Grandchamp, M., \& Cavassilas, J. F. (1997). Restauration d'images marines issues d'un radar à ouverture synthétique par filtrage adapté et technique multivues. Paper presented at the Seizième Colloque Gretsi, Gronoble.

Hadria, R., Duchemin, B., Baup, F., Le Toan, T., Bouvet, A., Dedieu, G., \& Le Page, M. (2009). Combined use of optical and radar satellite data for the detection of tillage and irrigation operations: Case study in Central Morocco. Agricultural Water Management, 96(7), 1120-1127. https://doi.org/10.1016/j.agwat.2009.02.010 
Hadria, R., Duchemin, B., Jarlan, L., Dedieu, G., Baup, F., Khabba, S.,... Le Toan, T. (2010). Potentiality of optical and radar satellite data at high spatio-temporal resolutions for the monitoring of irrigated wheat crops in Morocco. International Journal of Applied Earth Observation and Geoinformation, 12, Supplement 1(0), S32-S37. https://doi.org/10.1016/j.jag.2009.09.003

Kalluri, S., Gilruth, P., \& Bergman, R. (2003). The potential of remote sensing data for decision makers at the state, local and tribal level: Experiences from NASA's Synergy program. Environmental Science \& Policy, 6(6), 487-500. https://doi.org/10.1016/j.envsci.2003.08.002

Laur, H., Bally, P., Meadows, P., Sanchez, J., Schaettler, B., Lopinto, E., \& Esteban, D. (2002). Derivation of the Backscattering Coefficient $\sigma o$ in Esa Ers Sar Pri Products (p. 56). ES-TN-RS-PM-HL09.

Lionboui, H., Benabdelouahab, T., Elame, F., Hasib, A., \& Boulli, A. (2016). Multi-year agro-economic modelling for predicting changes in irrigation water management indicators in the Tadla sub-basin. International Journal of Agricultural Management, 5(4), 96-105. https://doi.org/10.5836/ijam/2016-05-96

Lionboui, H., Benabdelouahab, T., Hasib, A., Elame, F., \& Boulli, A. (2018). Dynamic Agro-Economic Modeling for Sustainable Water Resources Management in Arid and Semi-arid Areas. In C. M. Hussain (Ed.), Handbook of Environmental Materials Management (pp. 1-26). Cham: Springer International Publishing. https://doi.org/10.1007/978-3-319-58538-3_114-1

Mattia, F., Le Toan, T., Picard, G., Posa, F. I., D'Alessio, A., Notarnicola, C., ... Pasquariello, G. (2003). Multitemporal C-band radar measurements on wheat fields. IEEE Transactions on Geoscience and Remote Sensing, 41(7 Part I), 1551-1560. https://doi.org/10.1109/TGRS.2003.813531

McNairn, H., Merzouki, A., Pacheco, A., \& Fitzmaurice, J. (2012). Monitoring Soil Moisture to Support Risk Reduction for the Agriculture Sector Using RADARSAT-2. IEEE Journal of Selected Topics in Applied Earth Observations and Remote Sensing, 5(3), 824-834. https://doi.org/10.1109/JSTARS.2012.2192416

Ouyang, Z.-T., Zhang, M.-Q., Xie, X., Shen, Q., Guo, H.-Q., \& Zhao, B. (2011). A comparison of pixel-based and object-oriented approaches to VHR imagery for mapping saltmarsh plants. Ecological Informatics, 6(2), 136-146. https://doi.org/10.1016/j.ecoinf.2011.01.002

Ozdogan, M., Yang, Y., Allez, G., \& Cervantes, C. (2010). Remote Sensing of Irrigated Agriculture: Opportunities and Challenges. Remote Sensing, 2(9), 2274-2304. https://doi.org/10.3390/rs2092274

Picard, G., Le Toan, T., \& Mattia, F. (2003). Understanding C-band radar backscatter from wheat canopy using a multiple-scattering coherent model. IEEE Transactions on Geoscience and Remote Sensing, 41(7), 1583-1591. https://doi.org/10.1109/TGRS.2003.813353

Saich, P., \& Borgeaud, M. (2000). Interpreting ERS SAR signatures of agricultural crops in Flevoland, 1993-1996. IEEE Transactions on Geoscience and Remote Sensing, 38(2), 651-657. https://doi.org/ $10.1109 / 36.841995$

Snoeij, P., Attema, E., Davidson, M., Floury, N., Levrini, G., Rosich, B., \& Rommen, B. (2008). Sentinel-1, the GMES Radar Mission. IEEE Radar Conference, 48(4), 1-5.

Yang, C., Everitt, J. H., \& Murden, D. (2011). Evaluating high resolution SPOT 5 satellite imagery for crop identification. Computers and Electronics in Agriculture, 75(2), 347-354. https://doi.org/10.1016/j.compag. 2010.12.012

\section{Copyrights}

Copyright for this article is retained by the author(s), with first publication rights granted to the journal.

This is an open-access article distributed under the terms and conditions of the Creative Commons Attribution license (http://creativecommons.org/licenses/by/4.0/). 